\title{
ARTHROPLASTY OF THE ELBOW
}

\author{
TWENTY YEARS' EXPERIENCE OF A NEW APPROACH
}

\author{
KENYA TSUGE, TSUNEJI MURAKAMI, YUJI YASUNAGA, RAMSUNDAR RAM KANAUJIA
}

From the Hiroshima University School of Medicine

\begin{abstract}
We report the use of a new approach for elbow arthroplasty in 58 cases over a 20-year period. A wide exposure, obtained by elevating the triceps attachment and dividing the radial collateral ligament, allows the excision of diseased tissue, articular irregularities and osteophytes. Normal anatomy is restored and active mobilisation can be started 10 days after operation.

Good or fair results, with over $70^{\circ}$ of joint movement, were achieved in $88 \%$ of cases.
\end{abstract}

The reliable restoration of function to the stiff elbow remains an unsolved problem. Ollier in 1885 first reported subperiosteal excision of an ankylosed tuberculous elbow, and a number of methods of resection arthroplasty have been used, most gaining movement at the expense of lateral stability. Various materials have been used as interpositional membranes, including fascia lata, capsule, fat, gelfoam, nylon and silicone, but such procedures remain complicated and the results are uncertain.

We report the use of a simple technique in 43 patients with encouraging results after at least three years' follow-up in each case.

\section{PATIENTS AND METHODS}

Between 1964 and 1984, we performed elbow arthroplasties on 58 patients (Tsuge and Nagayama 1972; Sumida, Murakami and Adachi 1982). Of these, 31 males and 12 females have been followed-up for more than three years and are reported in detail. Their ages ranged from 3 to 66 years (average 28 years) and the cause of the stiff elbow was old trauma in 29, heterotopic ossification after prolonged coma in eight, osteoarthritis in four and osteomyelitis in two. Interposition of fascia lata was used in only seven cases, those with severe articular destruction.

Operative technique. The operation is performed with the patient supine and with the affected arm held over the

K. Tsuge, MD, Emeritus Professor

T. Murakami, MD, Assistant Professor

Y. Yasunaga, MD, Senior Resident

R. R. Kanaujia, MS (Orth), Postdoctoral Student

Department of Orthopaedic Surgery, Hiroshima University School of

Medicine, Kasumi 1-2-3, Hiroshima, Japan 734.

Requests for reprints should be sent to Professor K. Tsuge.

(C) 1987 British Editorial Society of Bone and Joint Surgery $0301-620 X / 87 / 1025 \$ 2.00$ chest. Below a high tourniquet, an S-shaped posterolateral incision starts $10 \mathrm{~cm}$ proximal to the lateral epicondyle, curves over the base of the olecranon and ends about $3 \mathrm{~cm}$ down the posterior border of the ulna (Fig. 1).

Subcutaneous dissection starts on the medial side; the ulnar nerve is released and a tape placed around it. The lateral epicondyle and supracondylar ridge are then exposed and a deeper incision made to separate the triceps from the brachioradialis and the forearm extensors. The triceps is stripped subperiosteally from the humerus and the proximal anconeus is elevated from the capsule and the olecranon (Fig. 1).

The triceps insertion is then elevated by careful sharp dissection from the olecranon, and remains in continuity with the periosteum of the ulna as they are reflected ulnarwards (Fig. 2). This exposes most of the posterior aspect of the elbow, with the exception of the ulnar side. The anterior aspect of the elbow is exposed by the subperiosteal dissection of the attachments of brachioradialis and extensor carpi radialis longus from the humerus and the distal part of the anconeus from the ulna, with reflection of the soft tissues medially and forwards. The radial collateral ligament is identified and divided by a $Z$ incision to allow for later repair. The elbow can then be opened in a varus direction and after further stripping of the anterior capsule from the coronoid process the joint can be dislocated (Fig. 3).

Contracted soft tissue, scar and heterotopic bone are then excised and the joint surfaces and any osteophytes are trimmed. If more exposure of the ulnar aspect of the joint is needed, this can be gained by subperiosteal dissection on the medial side of the olecranon to expose the attachment of the ulnar collateral ligament to the the coronoid process, shown by an arrow in Figure 4 . The posterior oblique, fan-like part of the ligament may be excised to improve access, but it is essential to preserve 

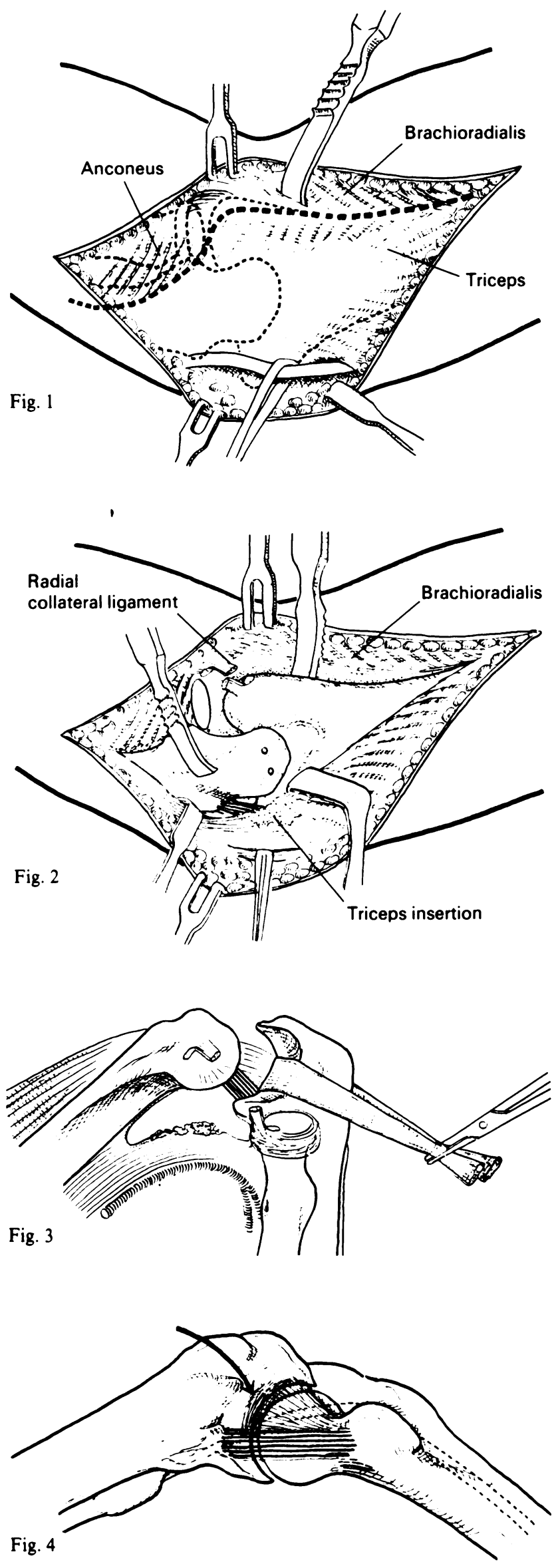

the strong cord-like anterior part. It is then possible to dislocate the elbow completely, but care must be taken to avoid traction injury to the ulnar nerve.

On completion of debridement the tourniquet is released and haemostasis is secured with bipolar diathermy. For cases with severe damage to the articular surfaces, fascia lata interposition may be required. The radial collateral ligament is repaired, and the triceps tendon with the periosteum of the ulna in continuity is secured with thread through two drill holes to the olecranon. For cases in which shortening of the triceps has occurred an improved range of flexion can be achieved by resection of part of the olecranon.

The muscles on the radial side are then sutured to close the original separation between brachioradialis, extensor carpi radialis longus and the triceps, and between anconeus and the periosteum of the ulna. Suction drains are inserted and the skin wound is closed. A posterior plaster slab holds the joint in $90^{\circ}$ of flexion for 10 days before active exercises are started. Some cases with flexion contracture of the elbow were treated with a turn-buckle splint for three to four weeks after operation.

\section{RESULTS}

Results were evaluated using the following grading (Knight and Van Zandt 1952):

Good. Range of movement of over $90^{\circ}$ in a useful arc with good stability and power.

Fair. Range of movement of over $70^{\circ}$ with satisfactory stability and adequate power for normal activities.

Poor. Range between $40^{\circ}$ and $70^{\circ}$ with no instability, or an adequate range of movement with some instability due to condylar deficiency.

Failure. Joint flail, or reankylosed, or arthrodesed for weakness or instability.

Follow-up in 43 cases was from 3 to 19 years (average 9 years 2 months). Results were good in 30, fair in eight, poor in four and a failure in one, giving $88 \%$ of satisfactory outcomes, equally distributed in the aetiological groups. These results are better than those reported using other methods (Kita 1977; Roberts and Pankratz 1979; Shahriaree et al. 1979).

The mean range of movement before operation was $35^{\circ}$ with an average improvement of $59^{\circ}$ to a postoperative mean of $94^{\circ}$. Most gain was in flexion; this and the results in the different aetiological groups is shown in

Figure 1 - Skin and deep incisions. A tape has been passed round the ulnar nerve. Figure 2 - Exposure of the joint. The triceps insertion is separated subperiosteally from the olecranon and remains in continuity with the periosteum of the ulna. The radial collateral ligament has been divided. Figure 3 - Exposure of the anterior and ulnar aspects of the elbow from the radial side. Anterior to the joint, scar tissue on brachialis muscle has been shown and the brachial artery is depicted. Figure 4 - Posteromedial approach to the ulnar collateral ligament. The attachment of the fan-shaped posterior part of the ligament to the ulna is arrowed. The anterior cord-like part of the ligament should be preserved. 


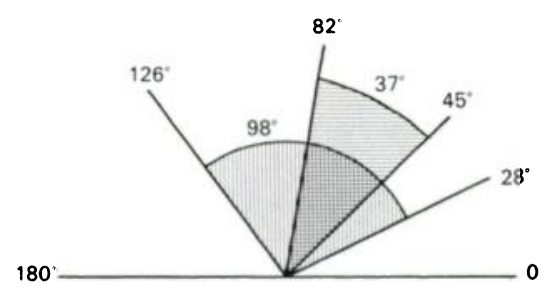

Figure 5 - Fractures and dislocations $(n=29)$.

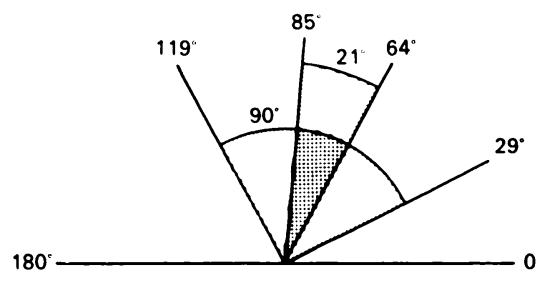

Figure 6 - Heterotopic ossification $(n=8)$.

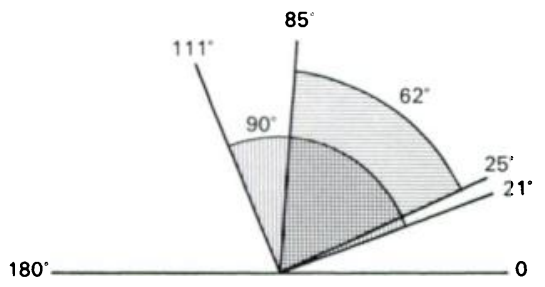

Figure 7 - Osteoarthritis $(n=4)$.

Diagrams to show the range of movement before and after arthroplasty in three groups of patients (pre-operative range, horizontal shading: postoperative, vertical shading).
Figures 5 to 7. Least improvement in range of movement was seen in the osteoarthritic patients, but these had remarkable pain relief and were all satisfied with their result. The good increase in range in the group with heterotopic ossification was probably due to the fact that the joint surfaces were relatively undamaged and because operation was always delayed until full maturation of the abnormal bone; the one failure was due to reankylosis at $90^{\circ}$ after an initially satisfactory result.

The seven cases in which fascia lata was interposed gained an average of $68^{\circ}$ movement as against an average of $58^{\circ}$ in those without interposition. Three of the interpositional arthroplasties showed some loss of lateral stability after operation, but this was brought under satisfactory control by muscle-strengthening exercises.

\section{ILLUSTRATIVE CASES}

Case 1. A 23-year-old man had sustained a comminuted fracture of the elbow (Fig. 8) in a side-swipe accident. This had been treated by open reduction and pinning, but six months later his range of movement was from $50^{\circ}$ to $70^{\circ}$ only. Five years after arthroplasty by the technique described his range of movement was $35^{\circ}$ to $115^{\circ}$ (Figs 9 and 10) with good stability and power. He was considered to have a fair result.

Case 2. A 27-year-old woman had an elbow ankylosed at $40^{\circ}$ by heterotopic ossification which had developed during prolonged bed rest for a severe psychiatric condition (Fig. 11). At arthroplasty seven months later calcification around the medial epicondyle and the olecranon was resected. Five years later the range of

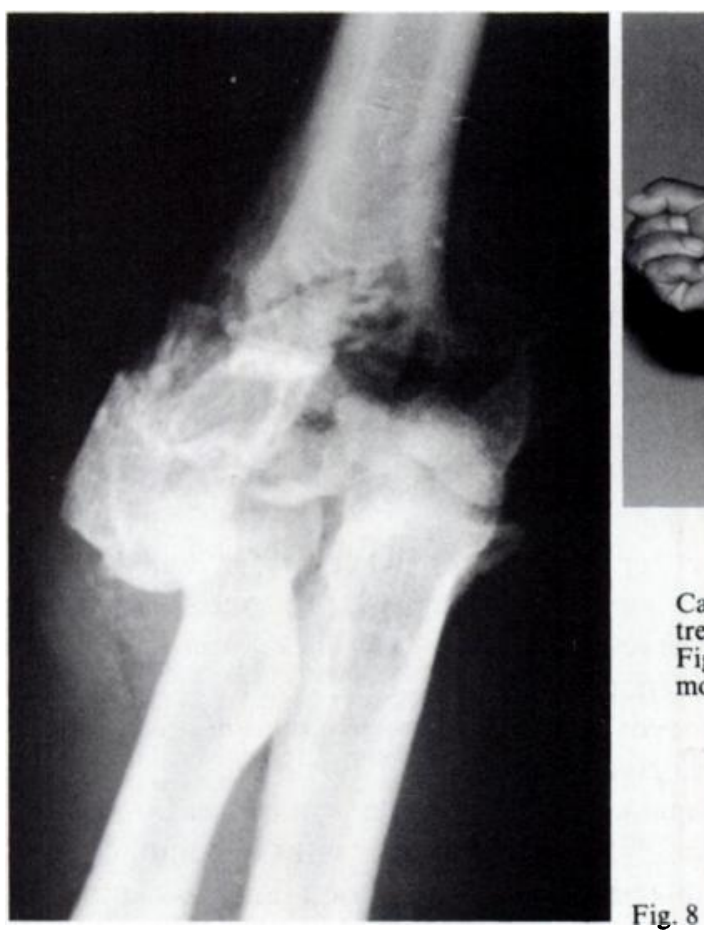




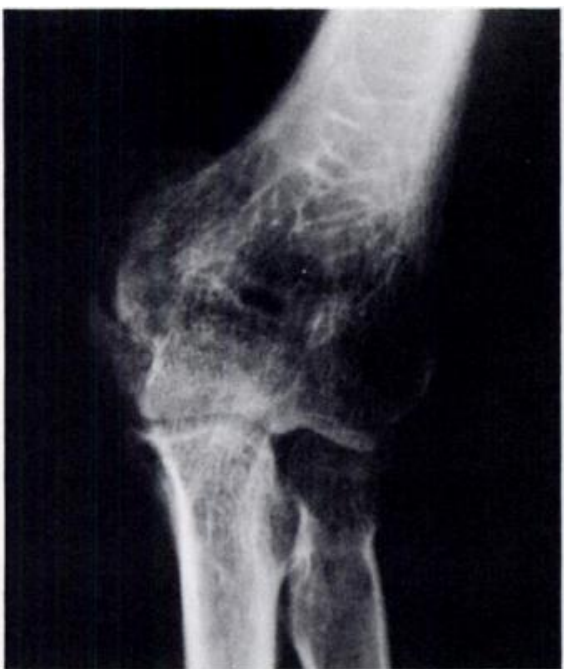

Fig. 11

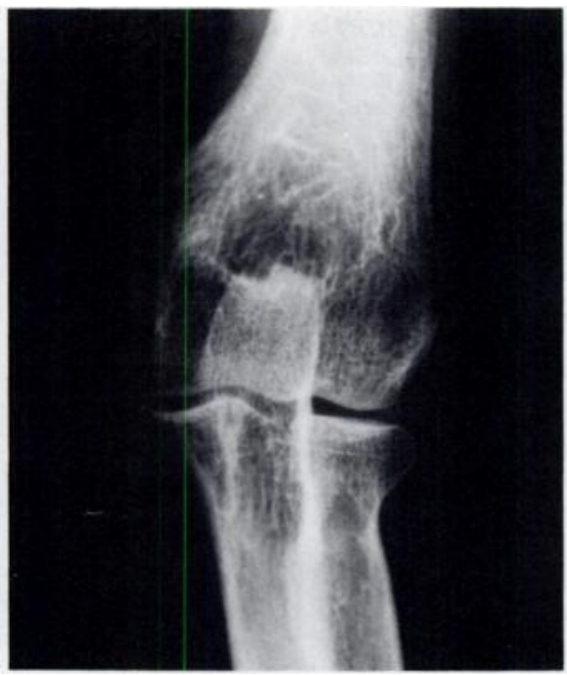

Fig. 12

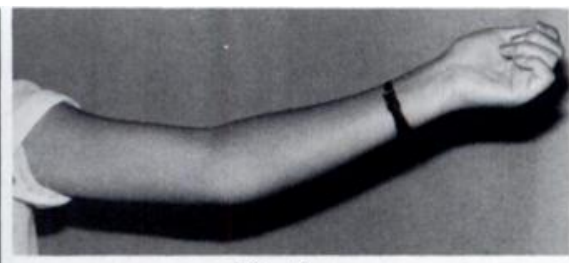

Fig. 13

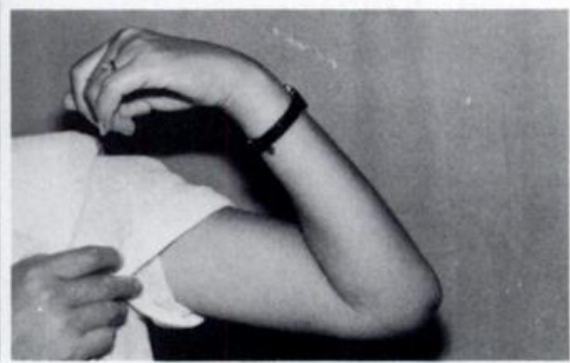

Fig. 14

Case 2. Figure 11 - Right elbow of a 27-year-old woman with heterotopic ossification and ankylosis at $40^{\circ}$ flexion. Figures 12,13 and $14-$ Five years after arthroplasty, showing radiograph and range of movement of $125^{\circ}$.

movement was $10^{\circ}$ to $135^{\circ}$ and the radiograph showed good articular surfaces (Figs 12, 13 and 14).

Case 3. A 61-year-old woman with osteoarthritis of the elbow (Fig. 15) suffered severe pain and had a range of movement of $40^{\circ}$ to $100^{\circ}$. After arthroplasty and the removal of many loose bodies she had good relief of pain and a range of movement from $30^{\circ}$ to $120^{\circ}$ (Fig. 16).

Case 4. A 29-year-old man sustained an open fracturedislocation of his right elbow and was referred to us eight months later when his range of movement was from $15^{\circ}$ to $45^{\circ}$ and the joint was still dislocated. Twelve years

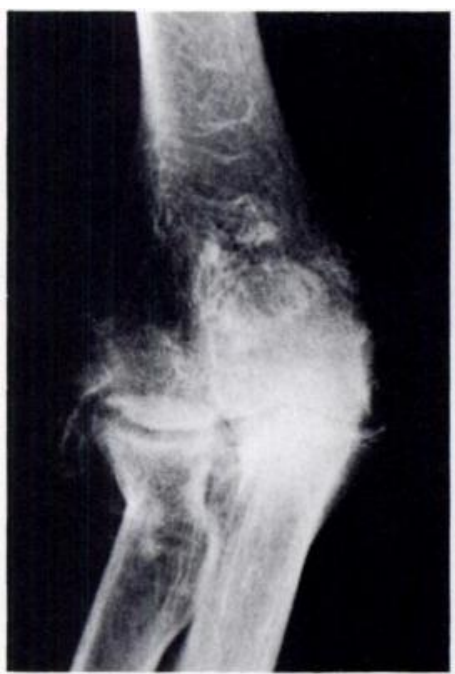

Fig. 15

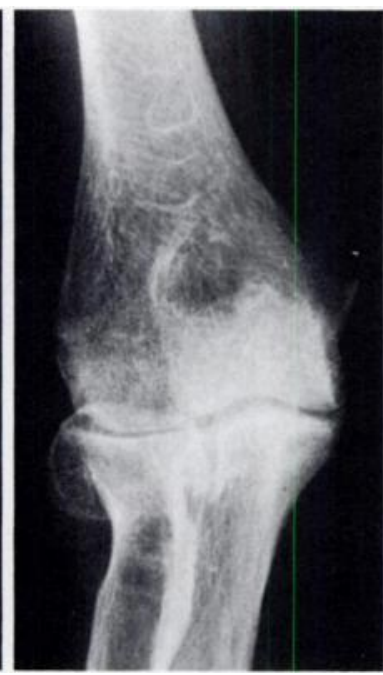

Fig. 16
Case 3. Figure 15 - Right elbow of a 61-year-old woman showing loose bodies and osteophytes due to osteoarthritis. She had pain and $60^{\circ}$ range of movement. Figure 16 - After operation the radiograph shows good clearance of the joint, with relief of pain and a range of movement of $90^{\circ}$. after arthroplasty the range of movement is $20^{\circ}$ to $125^{\circ}$ with only slight instability. The elbow gives no difficulty in normal activities.

\section{DISCUSSION}

Our method of arthroplasty simplifies the technique and allows wide exposure to permit the removal under direct vision of abnormal ossification, osteophytes and scar tissue without risk of injury to nerves and blood vessels. There is minimal trauma, anatomical reposition is possible and the restoration of the triceps attachment allows active mobilisation after 10 days. The divided radial collateral ligament heals without loss of stability.

The most difficult part of the operation is the removal of scar tissue around the ulnar side of the joint, and this frequently requires some stripping of the medial side of the coronoid process from both anterior and posterior approaches with excision of the fan-shaped posterior part of the ulnar collateral ligament. In three of the seven cases we treated for severe joint surface destruction by fascia lata interposition the joint remained unstable in maximal extension, but adequate stability was restored in all three cases by regular musclestrengthening exercises.

Other approaches to the elbow for this type of arthroplasty have been described, but none seem to give such reliable results. MacAusland (1947) used osteotomy of the olecranon, while Campbell (1922) turned down a tongue-shaped flap of the triceps tendon. Both these approaches give good access to the posterior part of the joint, but make anterior debridement difficult. Replacement arthroplasty carries greater risks of complications such as infection, bone resorption and loosening of components. 
Our technique allows excellent exposure by subperiosteal separation, retaining the continuity between the triceps tendon and the ulnar periosteum. It gives a wide, safe operative field and allows rehabilitation to begin early. The operation should be delayed in all cases until local tissue reaction has settled, myositis ossificans has matured or fractures have soundly united. The approach has also been used successfully for complete synovectomy in rheumatoid elbows and at early or delayed arthrotomy for open reduction of intra-articular fractures, though in this type of case there should be minimal stripping of soft tissues.

The optimal time for operation after severe injury is after about six months, but we agree with Roberts and Pankratz (1979) that heterotopic ossification should be allowed to mature for 1 to 2 years before excision is attempted. In all cases, good muscle strength should be restored by physiotherapy before operation is undertaken.
REFERENCES

Campbell WC. Arthroplasty of the elbow. Ann Surg 1922;76:615-23.

Kita M. Arthroplasty of the elbow using J-K membrane : an analysis of 31 cases. Acta Orthop Scand 1977;48:450-5.

Knight RA, Van Zandt IL. Arthroplasty of the elbow: an end-result study. J Bone Joint Surg [Am] 1952;34-A:610-8.

MacAusland WR. Arthroplasty of the elbow. New Engl $J$ Med 1947;236:97-9.

Roberts JB, Pankratz DG. The surgical treatment of heterotopic ossification at the elbow following long-term coma. J Bone Joint Surg [Am] 1979;61-A:760-3.

Shahriaree H, Sajadi K, Silver CM, Sheikholeslamzadeh S. Excisional arthroplasty of the elbow. J Bone Joint Surg [Am] 1979; 61-A:922-7.

Sumida Y, Murakami T, Adachi N. Elbow arthroplasty in our clinic Seikeigeka to Saigaigeka (Orthopaedics and Traumatology [Japanese]) 1982;30:740-6.

Tsuge K, Nagayama G. Mobilization of the elbow joint: elbow arthroplasty. Shujutsu (in Japanese) 1972;26:160-6.

Unander-Scharin L, Karlholm S. Experience of arthroplasty of the elbow. Acta Orthop Scand 1965;36:54-61. 